\title{
Activation Times in the Ventricular Myocardial Band
}

\author{
Trainini Jorge ${ }^{1 *}$, Elencwajg Benjamín ${ }^{2}$ and Herreros Jesús ${ }^{3}$ \\ ${ }^{1}$ Cardiac Surgery Department, Presidente Perón, Argentina \\ ${ }^{2}$ Electrophysiology Department, Hospital Presidente Perón, Argentina \\ ${ }^{3}$ Cardiovascular and Thoracic Department, Universidad Católica San Antonio (UCAM), Spain
}

Submission: March 09, 2017; Published: April 07, 2017

*Corresponding author: Trainini Jorge, Cardiac Surgery Department, Presidente Perón, Brandsen 1690 3er piso Dto A, (1287) Ciudad Autónoma de Buenos Aires República, Argentina, Email: jctrainini@hotmail.com

\section{Opinion}

The sequence of left ventricular endo and epicardial electrical activation was studied in patients by threedimensional electroanatomic mapping with a Carto navigation and mapping system (Biosense Webster, California, USA), which allows a three-dimensional anatomical representation with activation maps and electrical propagation. The propagation time of electrical activation was measured in milliseconds (ms). Isochronic and activation sequence maps were constructed and correlated with the surface electrocardiogram. Apical, lateral and basal views were obtained.

As the descending band is endocardial and the ascending band epicardial, two approaches were used to perform mapping. The endocardial access was achieved by conventional atrial transeptal puncture and the epicardial one by a percutaneous approach in the pericardial space. Endocardial and epicardial mapping was immediately and consecutively performed.

Figure 1 shows the propagation of endocardial and epicardial activation. In every pair of figures, the left panel shows the right lateral projection and the right panel the simultaneous left anterior oblique projection. The activated zones at each moment are shown in red. The activation of the descending band and ascending band segments constituting the left ventricular structure in the rope model [1] is represented below each pair of figures. The depolarized area at that moment is represented in red and those areas previously activated and in refractory period are represented in blue. Mean propagation time of the electrical activation through the ventricular myocardial band is observed beside each rope.

The activation of the left ventricle initiates in the interventricular septum, $12.4 \mathrm{~ms} \pm 1.816 \mathrm{~ms}$ after activation stars (Figure 1A). An epicardial area is also activated at that moment-the ascending band segment- evidencing radial activation at a point that we called the "crossing of band segments". This activation starts $25.8 \mathrm{~ms} \pm 1.483 \mathrm{~ms}$ after septal stimulation (Figure 1B) and $38.2 \mathrm{~ms} \pm 2.135$ after the initiation of cardiac activation. Simultaneously, it extends axially towards the ventricular apex, following the anatomical arrangement of the descending band segment at a mean time of $58 \mathrm{~ms} \pm 2.0 \mathrm{~ms}$ (Figure 1C \& 1D). After the "crossing of band segments", the activation loses its unidirectional character and becomes more complex. Three simultaneous wave fronts are generated:

1. The distal activation of the descending band segment towards the apical loop.

2. The depolarization of the ascending band segment from the crossing point towards the apex.

3. The activation of this band segment from the crossing point towards the final end of the muscular band in the aorta.
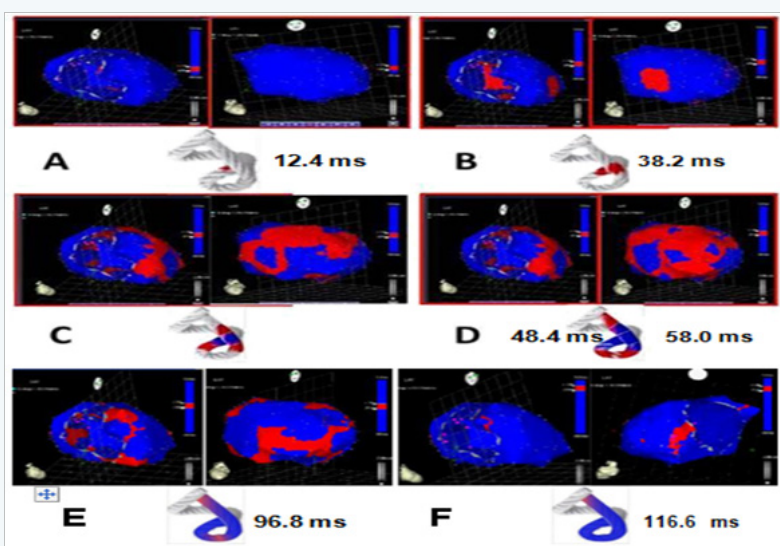

Figure 1: Propagation of endocardial and epicardial activation.

Figure 1D, 1E \& $1 \mathrm{~F}$ show the progression and end of this process. This investigation was the first in humans. 
Finally, there is another fact that strongly reinforces this interpretation; we have indicated that the normal pathway for left ventricular catheter implantation is through the coronary sinus, which gives access to the left ventricular epicardial veins, so that activation propagates from the endocardium to the epicardium. Although the catheter is properly located in the mentioned «effective area», there are some "nonresponder» patients. In recent studies [2] 20\% of patients are non-responders although the catheter implanted through the coronary sinus is perfectly positioned. When implanted through an endocavitary pathway, $50 \%$ of these patients become responders. The explanation using the classical conception is a fairly vague consideration in the sense that endo-epicardial activation is «more physiological» than the reverse.

From the perspective of our research, the explanation is much more coherent. The activation of the ascending band at the point of band intersection restores its longitudinal activation, with the beneficial consequences mentioned above. However, the radial activation from the descending to the ascending band and the persistent normal distal activation of the descending segment is lost. Endocavitary stimulation (descending segment) would almost completely restore the normal electrical activation and therefore its mechanical result.

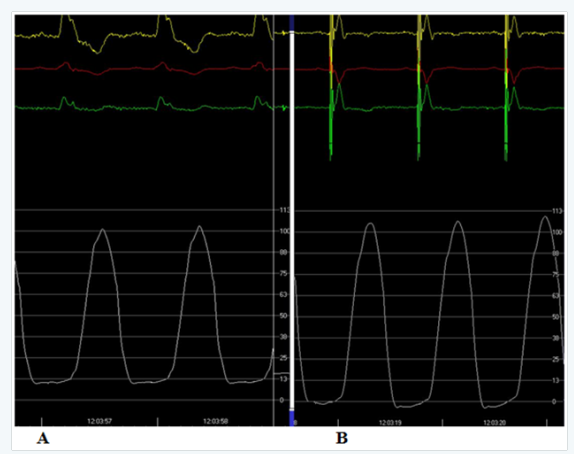

Figure 2: $(A)$ Is shown the left ventricular pressure curve in patient with left bundle block, the resynchronization device turned off. (B) The resynchronization device turned on.
Based on this principle, in Figure 2A is shown the left ventricular pressure curve in patient with left bundle block. The resynchronization device turned off. In the same patient (Figure 2B), the device turned on. Note in the pressure scale at the right of each panel (in $\mathrm{mm} \mathrm{Hg}$ ) the decrease of diastolic pressure from 13 to $0 \mathrm{~mm} \mathrm{Hg}$ when the ventricles are resynchronized. There is also a $10 \mathrm{~mm} \mathrm{Hg}$ increase in systolic pressure.

According to these concepts [3], we may infer:

a) Endo-epicardial three-dimensional mapping shows an electrical activation sequence in the area of the apex loop in agreement with the synchronic contraction of the descending and ascending band segments.

b) The simultaneous and opposing activation of the ascending band segment to the starting point of its radial activation from the descending band segment is consistent with the simultaneous reverse rotation of the apical and basal areas (ventricular torsion mechanism).

c) Late activation of the ascending band segment, compatible with its persistent contraction during the initial phase of isovolumic diastole.

The novel activation sequence of the Torrent Guasp muscle band found in the present paper, would explain the process systolic ventricular torsion and the effect of active suction in the is volumic diastolic phase.

\section{References}

1. Torrent Guasp F (1987) Estructura y mecánica del corazón. Grass (Ed.), Barcelona.

2. Morgan J, Biffi M, Geller L, Ruffa F, Leclercq C, et al. Novel superioraccess, atrial transseptal approach to left ventricular endocardial lead implantation, feasibility and safety results of the alternate site cardiac resynchronización (Alsync) study.

3. Trainini JC, Elencwajg B, López Cabanillas N, Herreros J, Lago N, et al. (2015) Basis of the New Cardiac Mechanics. The Suction Pump. Rev Argent Cardiol ( $1^{\text {st }}$ edn), Lumen, pp. 1-112.

Your next submission with Juniper Publishers will reach you the below assets

- Quality Editorial service

- Swift Peer Review

- Reprints availability

- E-prints Service

- Manuscript Podcast for convenient understanding

- Global attainment for your research

- Manuscript accessibility in different formats ( Pdf, E-pub, Full Text, Audio)

- Unceasing customer service

Track the below URL for one-step submission https://juniperpublishers.com/online-submission.php 